\title{
Pulse Density Modulation Based Series Resonant Inverter Fed Induction Heater System
}

\author{
S. Jaanaa Rubavathy ${ }^{1}$, P. Murugesan ${ }^{2}$ \\ ${ }^{1}$ Faculty of Electrical and Electronics Engineering, Sathyabama University, India \\ ${ }^{1}$ Department of EEE, Jeppiaar SRR Engineering College, Chennai, India \\ ${ }^{2}$ Department of Electrical \& Electronics Engineering,, S.A Engineering College, Chennai, India
}

\begin{tabular}{l} 
Article Info \\
\hline Article history: \\
Received Oct 30, 2017 \\
Revised Jan 29, 2018 \\
Accepted Feb 12, 2018 \\
\hline
\end{tabular}

\section{Keyword:}

Induction heating

PDM control

Resonant inverters

Series resonant inverter

\begin{abstract}
This paper deals with implementation of a multi-output Series Resonant Inverter(SRI) for induction heating applications, which uses pulse density modulation(PDM) control for full bridge Series resonant inverters for output voltage and power control. It ensures better efficiency performances than conventional control strategies. The proposed converter can be considered as a two output extension of a full bridge inverter. This full bridge inverter can control the two outputs, simultaneously and independently, up to their rated powers, which reduces the usage of number of components as compared with conventional method. It also ensures higher utilization of switches used for its operation. A two output full bridge series resonant inverter is simulated and implemented. The Experimental results are compared with the simulation results.
\end{abstract}

Copyright $(0) 2018$ Institute of Advanced Engineering and Science. All rights reserved.

\section{Corresponding Author:}

S.Jaanaa Rubavathy, Departement of Electrical and Electronics Engineering, Jeppiaar SRR Engineering College, Padur, Chennai, Tamilnadu, India.

Email: jaanaaruba@gmail.com

\section{INTRODUCTION}

Resonant inverters are now used in many applications to convert the available dc energy into ac energy such as DC-DC resonant converters, induction heating systems for industrial processes or home appliances, electronic ballasts for lighting, radio transmitters and others. The Control of output voltage or power in many resonant inverters has been obtained by varying the switching frequency, which has several disadvantages such as a wide noise spectrum which makes it difficult to control electromagnetic interference (EMI), more complex filtering of output-voltage ripple, a poor utilization of magnetic components. These problems can be eliminated with the use of a fixed-frequency or a narrow frequency range control technique.

Induction cookers are low power, maximum output induction heating system usually less than $3 \mathrm{KW}$ per load. An induction heating cooking appliance is basically made up of a flat-type induction coil on which the pan to be heated is placed. Between the pan and the coil an insulator (usually a ceramic glass) is placed. The heat is generated at the bottom of the pan due to eddy currents and hysteresis losses. These induced currents are caused by an alternating magnetic field generated by a medium frequency $(20-100 \mathrm{~Hz})$ current through the coil. Pan-induction coupling is usually modeled as the series connection of an inductor and a resistor, based on the transformer analogy. The values of the equivalent inductance and resistance depend on the operating frequency and the required maximum power.

A general block diagram of an induction heating cooking appliance is shown in Figure 1. Induction cookers take the input energy from the ac mains voltage, which is rectified by a diode bridge rectifier. A bus filter is designed to allow a big voltage ripple getting a resultant power factor close to one. Then the inverter topology is used to supply the high-frequency current to the induction coil. Due to this ripple all components 
have to be designed for the voltage and current peak values. The commonly used inverter topologies used in induction cookers are resonant inverters, including full-bridge [1], half bridge [2], [3], [4] \& [5] and single switch inverters. In this paper, Full bridge series resonant inverter topology is used for supplying the Induction Heating load.

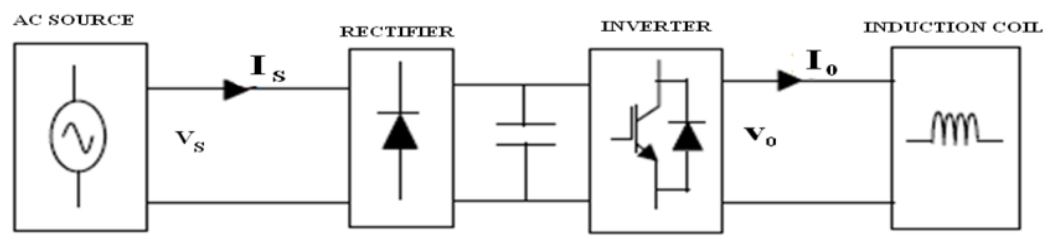

Figure 1. General block diagram of an IH cooking appliance

The objective of this paper is to define and analyze a PDM control technique for resonant inverters, so called asymmetrical voltage-cancellation (AVC) control. Previously in [6], State-Space Model has been used for switched converters for generating a two-output series resonant inverter for multi-burner induction cooking appliances. Now it is obtained by fixed frequency control [7 \& 8]. Later to this in [9], an inverter is designed to give three outputs for induction heating cooking appliances, now it is designed as two output solution for induction heating cooking applications with full bridge inverter topology with fixed frequency control which reduces number of switching devices as $2 n+2$ instant of $4 n$ [10].

Thus the use of multi-output inverters has clear benefits for multi-burner cookers: higher utilization of electronics, higher maximum power and it is possible to share some components of the converter. The required fixed frequency control has some additional advantages, as reducing the electromagnetic noise spectrum and avoiding the acoustic noise due to different operating frequencies which cause low-frequency interferences amplified by the pans [10].

A synthesis method proposed for switched converters is applied here as a tool for generating the new inverter. In addition to this it also employs fixed frequency control technique [11], [12] \& [13] in particular PDM control. Semiconductor switches with high switching speed is normally preferred in Induction Heating (IH) applications. The IGBT switches were used in [14], which provides minimum onstate conduction losses, higher efficiency than the high voltage MOSFET switches. And a series resonant inverter with MOSFET switches was proposed to enhance the cooling arrangements and the power conversion efficiency in [15]. The multi output full bridge inverter topologies were discussed for controlling the output power by using Asymmetrical voltage cancellation (AVC) or asymmetrical Pulse Width Modulation (APWM) in [16 \& 17]. Behaviour of a high frequency Parallel Quasi Resonant Inverter fitted Induction Heater with different switching frequencies are presented in [18].

The above literature doesn't deal with embedded implementation of multi output series resonant inverter system. This work deals with modeling, simulation and implementation of multi output series resonant inverter. The paper is organized as follows. In section II the operation of proposed topology of two output series resonant inverter with PDM control is presented. In section III, simulation results of a twooutput series resonant inverter are presented. In section IV, Results and discussions of proposed work is presented. Experimental results of a prototype are presented in section V. Finally, the conclusions of the work are provided in section VI.

\section{PROPOSED SERIES RESONANT INVERTER TOPOLOGY}

One of the most popular resonant inverters is the full-bridge series resonant inverter shown in Figure 2. The basic specifications for the converter synthesis: a two-output series resonant inverter, with variable output power and a fixed frequency control. Two inductive loads should be supplied separately, up to their rated output powers, without losing the mentioned benefits of fixed frequency control strategies. And a softswitching operation is employed for obtaining better efficiency performance.

The operation of the full bridge topology is divided into 5 modes per cycle, which uses Pulse Density Modulation control with fixed frequency operation.

\section{Mode 1 : Re-generative mode}

In this mode the energy stored in load circuit is returned back to the DC source via freewheeling diodes D1, D4 for load 1 and D1, D6 for load 2. The output voltage is $+\mathrm{v}_{\mathrm{dc}}$ and direction of resonant current flows from load to source. The current flows till the stored energy is returned to the source. 


\section{Mode 2 : Power Mode}

In this mode the resonant load gets energy from the DC source via switches Q1, Q4 for load 1 \& Q1, Q6 for load 2. The output voltage is $+\mathrm{v}_{\mathrm{dc}}$ and direction of resonant current flows from source to load.

Mode 3 : Freewheeling mode

In this mode the energy does not transfer to any sides. The direction of resonant current is from source to load through the freewheeling diodes D3,Q1 for load 1 and D5,Q1 for load 2, the output voltage is zero during this mode.

\section{Mode 4 : Re-generative mode}

In this mode the energy stored in load circuit is returned back to the DC source via freewheeling diodes D2, D3 for load 1 and D2,D5 for load 2. The output voltage is $-\mathrm{v}_{\mathrm{dc}}$ and direction of resonant current flows from source to load. The current flows till the stored energy is returned to the source.

Mode 5 : Power Mode

In this mode the resonant load gets energy from the DC source via switches Q2,Q3 for load 1 \& $\mathrm{Q} 2, \mathrm{Q} 5$ for load 2. The output voltage is $-\mathrm{v}_{\mathrm{dc}}$ and direction of resonant current flows from load to source.

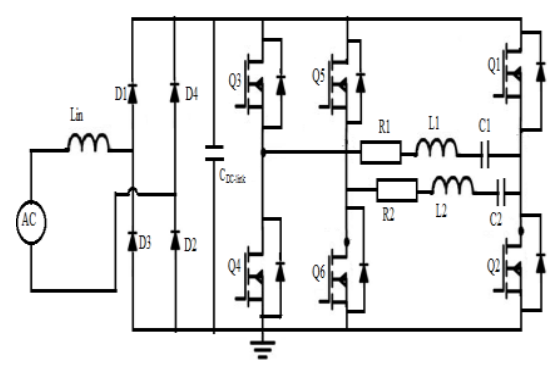

Figure 2. Two-output series resonant inverter for PDM control

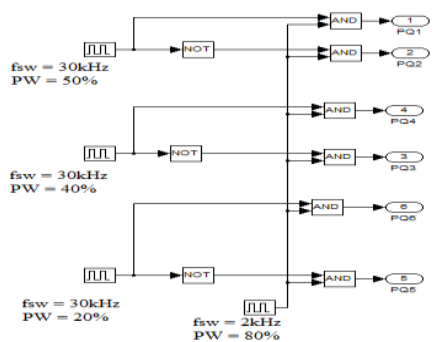

Figure 3. Pulse generation Circuit for PDM control

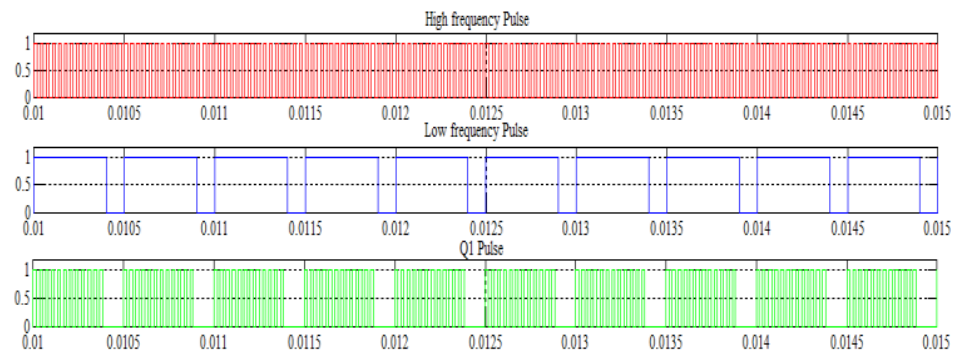

Figure 4. Typical waveforms of PDM control pulses for MOSFET 1

Figure 3 Shows the pulse generation circuit for PDM control used in multi output series resonant inverters. The pulse is generated by comparing the low frequency reference signal of $2 \mathrm{kHZ}$ is being compared with a high frequency carrier signal of $30 \mathrm{kHz}$. The duty cycle of common leg devices are given with $50 \%$ duty, first leg devices are given with $40 \%$ duty and the second leg devices are given with $20 \%$ duty. Figure 4 shows the typical waveforms of PDM control pulsesfor MOSFET 1.

\section{SIMULATION RESULTS}

The inverter circuit is simulated with MATLAB-Simulink software for verifying the operating principle of the multi-output series resonant inverter topology for induction heating applications. Parameters used for simulation are given in Table 1. 


\begin{tabular}{lr}
\multicolumn{2}{c}{ Table 1. Design Parameters } \\
\hline \multicolumn{1}{c}{ Parameter Name } & \multicolumn{1}{c}{ Values } \\
\hline Supply voltage, Vs & $230 \mathrm{~V}, 50 \mathrm{~Hz}, 1 \varphi$ \\
DC link capacitance, $\mathrm{C}_{\mathrm{dc}}$ & $1000 \mathrm{e}^{-6} \mathrm{~F}$ \\
Load Inductance, $\mathrm{L}$ & $1 \mathrm{e}^{-3} \mathrm{H}$ \\
Resonant Capacitor, & $28 \mathrm{e}^{-9} \mathrm{~F}$ \\
Load Resistance, R & $9.5 \Omega$ \\
Switching Frequency, $\mathrm{F}_{\mathrm{s}}$ & $30 \mathrm{kHz}$ \\
Duty Cycle of common leg, $\mathrm{D}_{\mathrm{C}}$ & $50 \%$ \\
Duty cycle of first leg, $\mathrm{D}_{1}$ & $40 \%$ \\
Duty Cycle of second leg, $\mathrm{D}_{2}$ & $20 \%$ \\
\hline
\end{tabular}

The Simulink model of full-bridge Series Resonant Inverter circuit is shown in Figure 5a which is modeled using RLC branches and MOSFET's. PDM Pulses for common leg, first leg and second leg switches are shown in Figs. 5b, 5c \& 5d. The output currents of load $1 \& 2$ are shown in Figs. 5e \& 5f. The voltage across loads $1 \& 2$ are shown in Figs. $5 \mathrm{~g} \& 5 \mathrm{~h}$. The variation of output power with respect to the load resistance is shown in Figure 5i. The variation of output power with respect to switching frequency is given in Figure 5j. The variation of output power with respect to the duty cycle is given in Figure 5k. The variation of output power with respect to duty cycle \& load resistance is shown in Figure 5l. The variation of output power with respect to switching frequency and load resistance is shown in Figure $5 \mathrm{~m}$. The output power increases when the input voltage is increased.

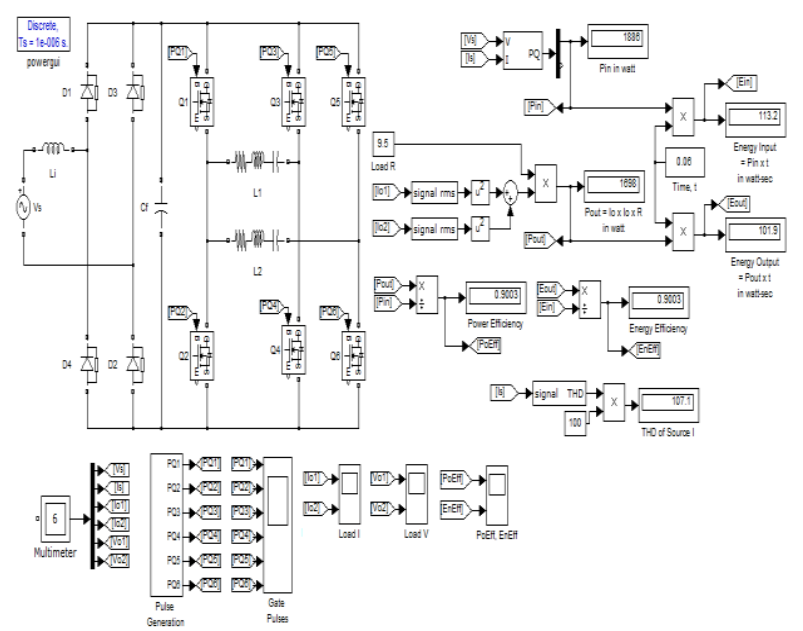

Figure 5a. Series resonant Inverter Circuit with PDM control for IH application

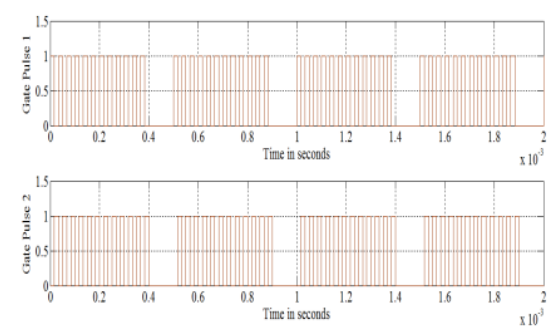

Figure 5b. Pulses for Common leg

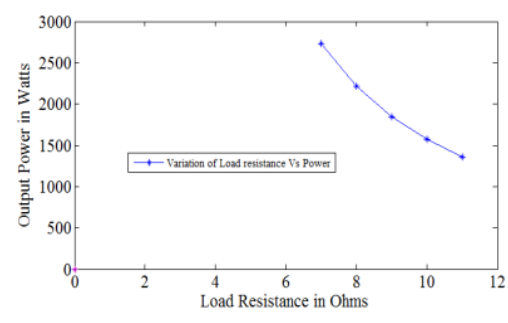

Figure 5g. Variation of Pout with Load resistance 


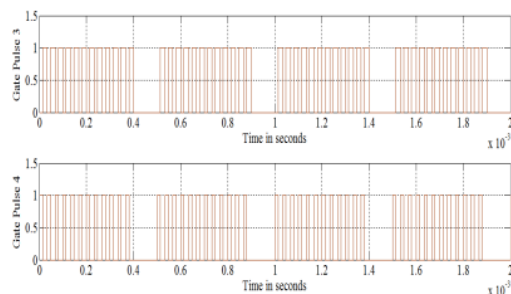

Figure 5c. Pulses for first leg
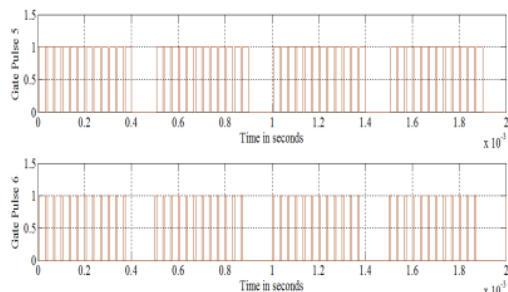

Figure 5d. Pulses for second leg

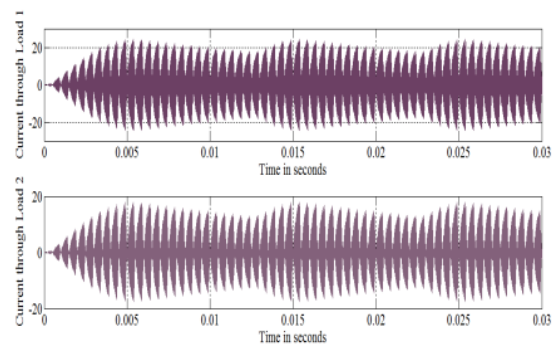

Figure 5e. Output current through load current $1 \& 2$

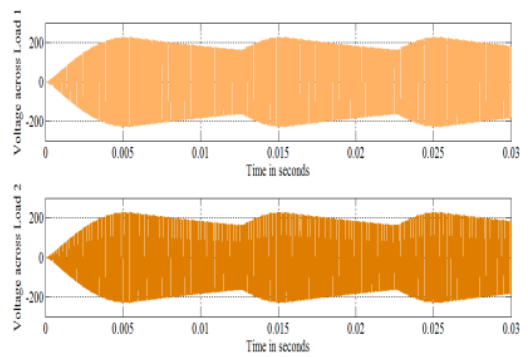

Figure 5f. Voltage across load $1 \& 2$

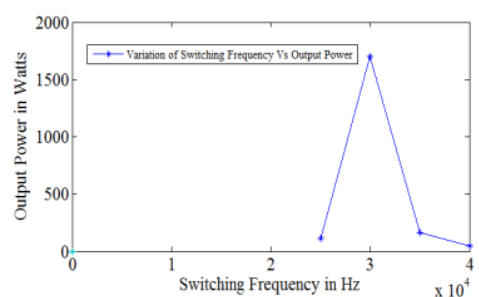

Figure 5h. Variation of Pout with $\mathrm{f}_{\mathrm{SW}}$

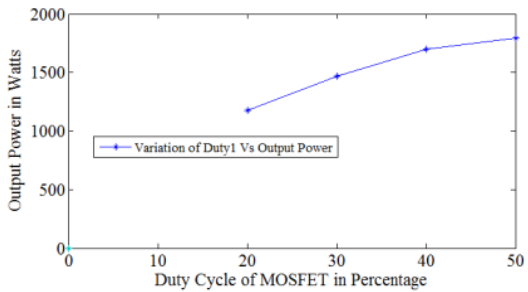

Figure 5i. Variation of Pout with Duty Cycle

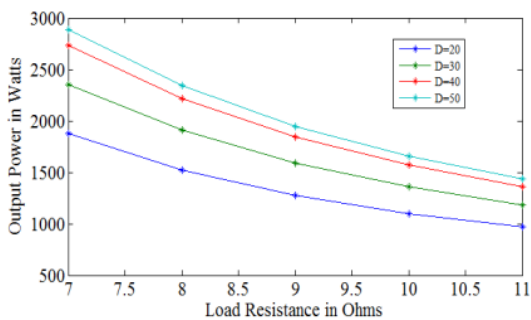

Figure 5j. Variation of Pout Vs Duty and $\mathrm{R}_{\mathrm{L}}$

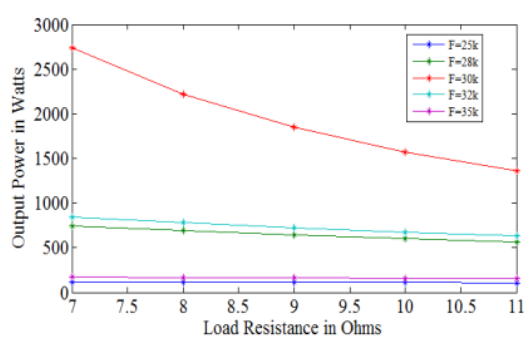

Figure 5k. Variation Pout Vs Fsw \& $\mathrm{R}_{\mathrm{L}}$

The performance parameters of full bridge series resonant inverter fed induction heating system are calculated by using the following formulae.

Input Power, $P_{\text {in }}=V I \cos \varphi$

Output Power, $P_{\text {out }}=\left[{I_{1}}^{2}+I_{2}{ }^{2}\right] \times R$

Power Efficiency, $\eta=\frac{P_{\text {out }}}{P_{\text {in }}}$

Switching Frequency, $f_{\text {swit }}=\frac{1}{T}$ 
Resonant Frequency, $f_{\text {reso }}=\frac{1}{[2 \pi \sqrt{L C}]}$

Total Harmonic Distortion, $T H D=\frac{\sum\left(I_{0 r m s}{ }^{2}+I_{1 r m s}\right)^{2}}{I_{1 r m s}}$

The measure of harmonic presence in a non-sinusoidal periodic waveform is represented by the equation (6). Where, Iorms is the root mean squared (RMS) value of any non-sinusoidal current and $\mathrm{I}_{1 \mathrm{rms}}$ is the root mean squared (RMS) value of the fundamental harmonic present in that current. It gives information about how close a non-sinusoidal waveform close to its fundamental in waveshape [18].

\section{RESULTS AND DISCUSSIONS}

In induction heating system the depth of penetration of heat is inversely proportional to the working frequency. And in general the periodicity is inversely proportional to the working frequency. Therefore the duty cycle of MOSFET is varied, to control the working frequency and the depth penetration of heat. In this paper, the proposed full bridge series resonant circuit is modelled and simulated under different switching frequencies such as $25 \mathrm{kHz}, 30 \mathrm{kHz}$ and $35 \mathrm{kHz}$ respectively. The proposed circuit is designed with the resonant frequency of $30.077 \mathrm{kHz}$. Thus around the switching frequency, the switching operations ensuring less switching losses with maximum efficiency. The selection of the switching frequency a little superior to resonant frequency is generally advantageous.

When the switching frequency is at $25 \mathrm{kHz}$ a reduced amount of the resonant frequency, then from Figure $5 \mathrm{~h}$, it is shown that the switching operation do not follow the resonant conditions that produces high switching losses and hence reduces the output power and efficiency. And the THD of the source current is excessive at this switching frequency, which results non-sinusoidal nature of source current and thus the input voltage may have unnecessary harmonics. In order to filterout this unnecessary harmonics an ac filter is needed at the input side and thus increases the cost of induction heating system. In addition, this reduced switching frequency may create an unwanted perceptible noise. So, the selection of lower switching frequency normally avoided.

When the switching frequency is at $35 \mathrm{kHz}$ higher than the resonant frequency may produce larger THD value of the output current and it is successful for induction heating purpose, but this is also not advisable because again the switching operation do not follow the resonant conditions and hence produce high switching losses which results lower output power and efficiency as shown Figure 5h.

Table 2. Performance parameters of Full Bridge SRI with PDM control

\begin{tabular}{cccccc}
\hline Inverter Type & $\begin{array}{l}\text { Vs } \\
(\mathrm{V})\end{array}$ & $\begin{array}{c}\text { Pin } \\
(\mathrm{W})\end{array}$ & $\begin{array}{c}\text { Pout } \\
(\mathrm{W})\end{array}$ & $\begin{array}{c}\text { Power } \\
\text { Efficiency } \\
(\%))\end{array}$ & $\begin{array}{c}\text { THD } \\
(\%)\end{array}$ \\
\hline FB_SRI_PDM & 230 & 1886 & 1698 & 90.03 & 107.1 \\
\hline
\end{tabular}

Performance analysis plots are also plotted for full bridge series resonant inverter fed induction heating system. The result shows that output power decreases for the increase of load resistance and also decreases with decrease in duty cycle. And the maximum output power is obtained with the switching frequency of 30 $\mathrm{kHz}$ for all other frequencies output power is reduced because the load circuit is tuned to frequency of $30 \mathrm{kHz}$. A simulation result shows that the two-output full bridge inverter topology gives an efficiency of $90.03 \%$ with the input voltage of $230 \mathrm{~V}$. Also the input current THD obtained is $107.1 \%$.

\section{EXPERIMENTAL RESULTS}

An experimental model of induction heating system with Series Resonant inverter has been built in order to verify the effectiveness of simulation results. Hardware module is shown in Figure 6a. Driving pulses for MOSFET's Q1 \& Q2 are shown in Figure 6b. Driving pulses for Q3 \& Q4 are shown in Figure 6c. Switching pulses for Q5 \& Q6 are shown in Figure 6d. Voltage across load 1 is shown in Figure 6e. Voltage across load 2 is shown in Figure $6 f$. 


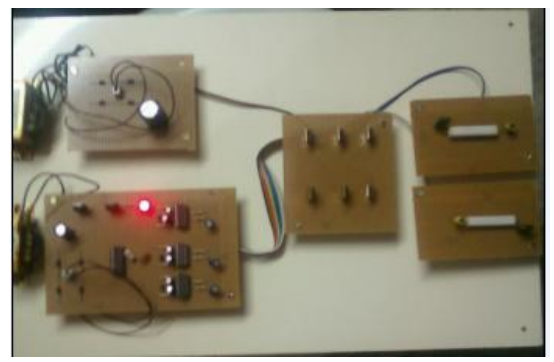

(a)

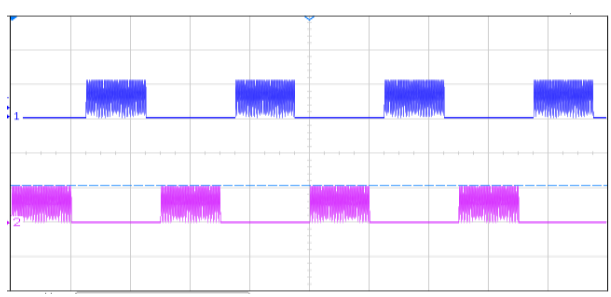

(c)

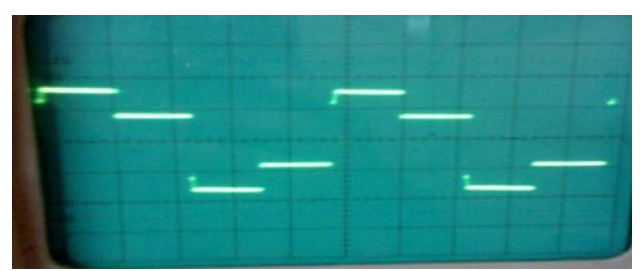

(e)

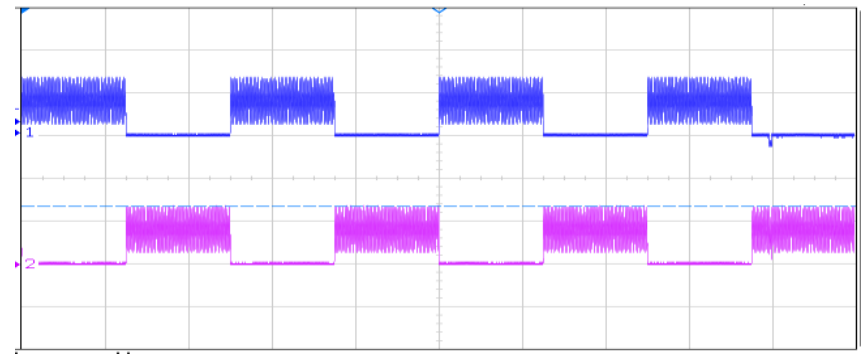

(b)

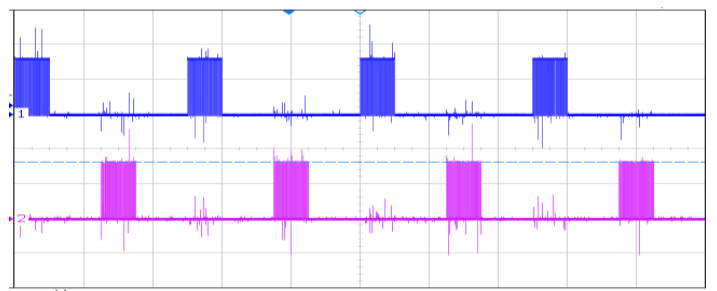

(d)

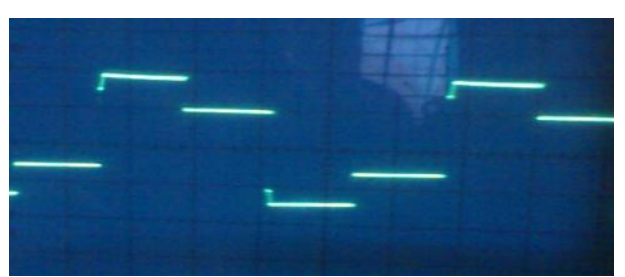

(f)

Figure 4 (a) Experimental model of series resonant inverter a) Experimental model. (b) Driving pulses for $\mathrm{Q}_{1} \& \mathrm{Q}_{2}$ (X-axis:9.5 $\mu$ s, $\mathrm{Y}$-axis: 3V/div). (c) Driving pulses for $\mathrm{Q}_{3} \& \mathrm{Q}_{4}$ (X-axis:9.5 $\mu \mathrm{s}, \mathrm{Y}$-axis: $3 \mathrm{~V} / \mathrm{div}$ ). (d)

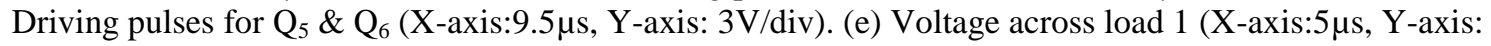
40V/div). (f) Voltage across load 2 (X-axis:5 $\mu$ s, Y-axis:40V/div)

\section{CONCLUSION}

Two output series resonant inverter system with Pulse Density Modulation Control is modeled using the blocks of Simulink and the results are presented. This inverter uses smaller values of L \& $\mathrm{C}$ since it operates at high frequency. Switching losses are reduced by using resonant switching. Higher amount of heat is generated with the use of two RLC branches. Variation of output power with the variation in the duty cycle, switching frequency, load resistance are also presented. The hardware is fabricated and tested in the laboratory. The experimental results are in line with the simulation results.

\section{ACKNOWLEDGEMENTS}

The authors would like to acknowledge the Faculty of Electrical and Electronics Engineering, Sathyabama University, Chennai for providing the laboratory facilities and necessary components to conduct simulation and protype model.

\section{REFERENCES}

[1] Francis P. Dawson \& Praveen Jain, “ A Comparison of load commutated inverter systems for induction heating and melting applications”, IEEE Transactions on Power Electronics, vol 6, No.3, pp 430-440, july 1991.

[2] Henry W. Koertzen, Jacobus D.van wyk \& Jan A. Ferreira " Design of the Half bridge series resonant converter for induction cooking", The $26^{\text {th }}$ Annaual Power Electronics specialist conference, vol 2, pp 729-735, 1995.

[3] Mokhtar kamli, Shigehiro yamamoto \& Minoru Abe, “A $50-150 \mathrm{kHz}$ Half bridge inverter for induction heating application”, IEEE Transactions on industrial electronics, vol 43, No 1, pp 163-172, Feb 1996.

[4] Jose M. Burdio, Abelardo Martinez \& Jose R. Garcia, “ A synthesis method for generating switched electronic converter", IEEE Transactions on Power Electronics, Vol 13, No 6, pp 1056-1068, Nov 1998. 
[5] Shengpei wang, Kiyoshi Izaki,Izuo Hirota, Hidekazu Yamashita, Hideki Omori Mutsuo Nakaoka, "InductionHeated cooking appliances using New Quasi-resonant ZVS-PWM inverter with power factor correction", IEEE Transactions on industrial applications, vol 34, No 4, pp 705-712, July/Aug 1998.

[6] Fernando Monterde, Pablo Hernandez, Jose M. Burdio, Jose R. Garcia \& Abelardo Martinez , “ A new ZVS Twooutput Series-resonant inverter for induction cookers obtained by a synthesis method", The $31^{\text {st }}$ Annual Power Electronics specialist conference, Vol 3 , pp 1375-1380, 2000.

[7] Jose M. Burdio, Luis A. Barragan, Fernando Monterde, Denis Narraro \& Jesus Acero, " Asymmetrical Voltage Cancellation control for Full bridge series resonant inverter" , IEEE transaction on Power Electronics, vol 19, no.2,pp 461-469, March 2004.

[8] Jose M. Burdio, Fernando Monterde, Jose R. Garcia, Luis A. Barragan, Abelardo Martinez, " A two output seriesresonant inverter for induction heating cooking appliances", IEEE transaction on Power Electronics, vol 20, No 4,pp 815-822, July 2005.

[9] S.H.Hosseini, A. Yazdenpanah Goharrizi and E. Karimi, “ A Multi-output Series-resonant inverter with Asymmetric voltage -cancellation control for induction heating cooking appliances", CES/ IEEE $5^{\text {th }}$ International conference on Power Electronics \& Motion control, vol 3, pp 1-6, 2006.

[10] J.Salmon, A.Knight, J. Ewanchuk, "Single phase multi level PWM inverter topologies using coupled inductor", IEEE Transaction on Power Electronics, pp 802-808, 2008.

[11] Pattanapong Kongsakorn and Anuwat Jangwanitlert, "A two-output high frequency series -resonant induction Heater", IEEE international conference on Electrical Engineering/ Electronics, Computer, Telecommunications \& Information technology, pp 842-845, 2010.

[12] Juan Dixan, Javier pereda,Carlos Castillo, Sebastian Bosch, “ Asymmetrical Multi level inverter for Traction drives using only one DC supply, IEEE Transactions on Vehicular Technology, Vol. 59, No.8, pp. 3736-3743, 2010.

[13] Booma Nagarajan, Rama Reddy Sathi \& Pradeep Vishnuram, “ Power tracking control of domestic induction heating using pulse density modulation with the Fuzzy logic controller", Journal of Electrical Engineering \& Technology, vol.9, No.6, pp.1978-1987, 2014.

[14] Pradip Kumar Sadhu, Palash Pal, Nitai Pa and Sourish Sanyal, "Selection of Power Semiconductor Switches in M.H.B.R.I. Fitted Induction Heater for Less Harmonic Injection in Power Line", International Journal of Power Electronics and Drive System (IJPEDS), Vol. 6, No. 1, March 2015, pp. 121 128.

[15] M.Saravanan and A.Ramesh Babu, "High Power Density Multi-MOSFET-Based Series Resonant Inverter for Induction Heating Applications", International Journal of Power Electronics and Drive System(IJPEDS), Vol. 7, No. 1, March 2016, pp. 107 113.

[16] Jaanaa Rubavathy.S and Murugesan.P, “ Experimental investications on multi-output Cyclo-inverter fed induction heater system", Australian Journal of Electrical and Electronics Engineering (AJEEE), Vol.10, Issue 4, pp 483-489, 2013.

[17] Jaanaa Rubavathy.S and Murugesan.P, "Simulation and Verification of a Multi output Series Resonant inverter fed Induction Heater system", IEEE International Conference on Power Electronics, Drives and Energy Systems (PEDES), December 16-19,Bengaluru,India, 2012.

[18] Avijit Chakraborty, Pradip Kumar Sadhu, Kallol Bhaumik, Palash Pal, Nitai Pal, "Behaviour of a High Frequency Parallel Quasi Resonant Inverter Fitted Induction Heater with Different Switching Frequencies” , International Journal of Power Electronics and Drive System(IJPEDS), Vol. 6, No. 2, April 2016, pp. 447 457.

\section{BIOGRAPHIES OF AUTHORS}

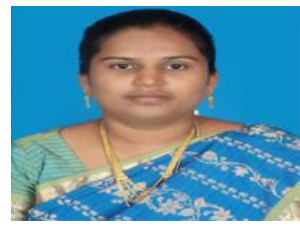

S.Jaanaa Rubavathy graduated with Bachelor of Electrical and Electronics Engineering from Erode Sengunthar Engineering College, Bharathityar University, Coimbatore in the year 2002. She has done her M.Tech degree in Power Electronics and Drives from SASTRA University, Tanjore in the year 2004. She is pursuing her PhD Sathyabama University in the area of Induction Heating. She has 13 years of teaching experience. Currently she is working as an Assistant Professor in Jeppiaar SRR Engineering College, Padur, Chennai. Her areas of research interest are Induction heating and Arc Welding power sources.

Mail id:jaanaaruba@gmail.com

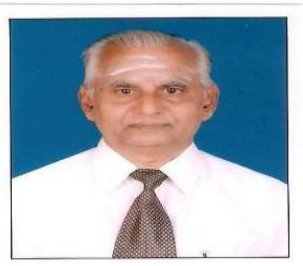

Dr.P.Murugesan received his B.E, degree from Government College of Technology, Coimbatore in the year 1964, M.E from Thiagarajar Engineering College, Madurai in the year 1982 and Ph.D degree from International University of Contemporary Studies, Washington D.C. in 2002. He has 36 years of experience in TNEB and 16 years of teaching experience in various Engineering Colleges. Presently he is working as a professor in S.A Engineering College, Chennai. Also he served as an External Faculty at Anna University Chennai for five Years. His area of research interest are Induction heating and Reactive Power Controllers.

Mail id:murugu1942@yahoo.co.uk. 